\title{
Are Increased Chronic Diseases a Potential Legacy of Cuba's Special Period?
}

\section{Gail A. Reed MS}

Cuba is the only country I know to erect a monument to the egg.... and so it should. Located on Havana's Fifth Avenue, the simple sculpture pays homage to the salva vida-literally the life saver of many a Cuban family, particularly in the 1990s. Those were the worst years of what was euphemistically called the "Special Period," when the economy careened ever downward, reeling from the loss of $85 \%$ of Cuba's aid and trade in the post-Soviet era.

Eggs became a symbol of the worst and the best of those times: in the 1980s, eggs were available at markets everywhere"liberated" from the list of subsidized staples rationed after the US embargo was imposed in the 1960s. But by 1991, they began to disappear from the shelves, only to reappear once again on the ration card: first 30 a month per person, then 15, then 8 . The worst was the disappearance; the best the fact that scarcity itself was rationed, enhancing the sense that Cubans would make it or not, together.

Similarly, the rest of the food basket began to dwindle, leaving shelves and dinner tables with meager offerings. To their credit, the authorities and the health system gave top priority for the little there was to young children, pregnant women and the elderly.

Family doctors and nurses were also literally next door, using their skills, dedication and few remedies at hand to help hold the line on Cuba's main health indicators, counting as they could on active community participation. Indeed, only small increases were recorded briefly in infant mortality and low birth weight. Meanwhile, specialists scoured the globe for friends who would send drugs for their more complex cases.

These efforts notwithstanding, a dramatic neuropathy epidemic related to nutrient deficiencies swept the country in 1992-93, affecting adults in their prime, and leaving nearly 50,000 temporarily blind or disabled. Only nationwide distribution of multivitamins turned the tide.[1]

Blackouts-announced in a press reduced to a single four-page newspaper and scant hours of radio and television-were also rationed, rolling from one community to another across the country. Cubans called them "light-ups," since neighborhoods were without electricity for 16 hours and with it for only 8 . In the heat of tropical summers, this meant no fans, no fridge and little TV for kids at home (where toys were also scarce). Almost everything was slowly fading away... public transport, gasoline, paper.

One million Chinese bicycles were imported to get to work and school; but upon arriving, many people found no tools or electricity to do their jobs. Cubans learned to stand in longer lines for less produce; to raise chickens and rabbits on their balconies; and to make just about anything from disfigured tomatoes harvested days before they reached market.

Paradoxically, during this time, rates of many traditional chronic non-communicable diseases decreased. Closer examination

reveals the logic: people were trimmer, then thinner; there was little or no money for cigarettes, rum or cooking lard; and walking and cycling had become a way of life.[2]

Yet the nineties were a time of nearly universal angst, parents wondering what would be left of their households, their families, their children's futures. Surely we have yet to see the long-term health effects of so many years of utter uncertainty-different from today's uncertainty, which is just as real, but tempered by (albeit uneven) economic growth and new options.

\section{Surely we have yet to see the long-term health effects of so many years of utter uncertainty} been clearly shown to adversely affect the immune system, while its association with cancer, heart disease, stroke and other chronic non-communicable diseases is well established. In years to come, will the omnipresent stress of the Special Period contribute to increased incidence of these diseases in Cuba's population, already one of the fastest aging in the Americas?

As Cuba's chronic disease burden continues to rise-with cancer now surpassing heart disease as the leading cause of deathhealth researchers would do well to look into the Special Period's legacy. Undoubtedly, it is there. $-1 /$ -

1. Mills C. In the Eye of the Cuban Epidemic Neuropathy Storm: Rosaralis Santiesteban MD PhD, Neurology and Neurosurgery Institute. [interview] MEDICC Rev 2013;13(1):10-15.

2. Franco M, Bilal U, Orduñez P, Benet M, Morejón A, Caballero B, et al. Population-wide weight loss and regain in relation to diabetes burden and cardiovascular mortality in Cuba 1980-2010: repeated cross sectional surveys and ecological comparison of secular trends. BMJ [Internet]. 2013 [cited 2013 Jun 26];346:f1515. Available from: http://www.bmj.com/content/346/bmj.f1515

Submitted: July 1, 2013

Approved for publication: July 16, 2013

Disclosures: None 